prospective study. Circulation, 469-476

4. S. S. Fujita M, Ohno A, Nakajima H, Asanoi H. (1987). Importance of angina for development of collateral circulation. Br Heart J, 57, 139-143.

5. S. G. B. G (1987). Coronary circulation on normal and pathologic heart.
6. M. D. DAVID C. LEVIN (1974). Pathways and Functional Significance of the Coronary Collateral Circulation. Circulation, 50, 831-836

7. A. Kurtul v và S. Ozturk (2017). Prognostic value of coronary collaterals in patients with acute coronary syndromes. Coronary Artery Disease, 28, 406-412.

\title{
BƯớC ĐẦU ĐÁNH GIÁ KẾT QUẢ CẤY MÁY TẠO NHİP VĨNH VIỄN HAI BUỒNG Ở' BỆNH NHÂN RỐI LOẠN NHİP TIM CHẬM TAI BẾNH VIẾN ĐA KHOA HÀ TĨNH
}

\section{TÓM TẮT}

Mục tiêu: Đánh giá hiệu quả kỹ thuật cấy máy tạo nhịp tịm vĩnh viễn (MTNTVV) 2 buồng. Đoối tương và phương pháp nghiên cứu: Nghiên cứu thuần tập tiến cứu trên 47 Bệnh nhânđược chẩn đoán các bênh RLNT chậm có chỉ định cấy MTNNTVV hai buồng được tiền hành cấy máy hai buồng nhĩ tphair và thất phải dưới màn tăng sáng tại bệnh viện đa khoa tỉnh Hà Tĩnh từ tháng 7/2017 - 4/2019. Kết quả: 47 bệnh nhân với 30 nam và 17 nữ, tuổi trung bình $61,4 \pm$ 11 9. Các bệnh lý chỉ định cấy máy tạo nhịp tim vĩnh viễn 2 buồng: Block nhî̃ thất cấp 2, cấp 3 chiếm tî lệ 42,6\%; hội chứng suy nút xoang chiếm tỉ lệ $57,5 \%$. Ngưỡng kích thích trung bình của điện cực tiểu nhî phải $0,9 \pm 0,2 \mathrm{~V}$; của điện cực thất phải $0,5 \pm 0,2 \mathrm{~V}$. Phân suất tống máu thất trái EF sau cấy máy 3 tháng trung bình đo được là $57,3 \pm 8,5$. Không có bệnh nhân nào có biến chứng như tràn máu màng ngoài tim, nhiễm trùng túi máy, sút dây điện cực. Kểt luận: Kỹ thuật cây MTNTVV 2 buồng là một phương pháp an toàn, hiệu quả, với tỉ lệ thành công cao vàbiến chứng thấp. Khi thực hiên thành công ở tuyến tỉnh, góp phânn giảm tải cho các bệnh viện ở tuyến trên.

Tư khóa: Cấy máy tạo nhịp vĩnh viễn 2 buồng, rối loạn nhịp tim chậm

\section{SUMMARY \\ EVALUATING THE EFFICIENCY OF TWO- CHAMBER IMPLANTATION OF A \\ PERMANENT PACEMAKER AT HA TINH POLYCLINICAL HOSPITAL}

Objective: Evaluate the efficiency of two-chamber implantation of a permanent pacemaker (MTNTVV). Subjects and methods: A prospective cohort study on 47 Patients diagnosed with delayed RLP with indication of two-chamber MTNTVV implantation underwent two-chamber atrial and right ventricular implantation under the light screen in the disease.

*Bệnh viện Đa khoa tỉnh Hà Tïnh

Chịu trách nhiệm chính: Lê Văn Dũng

Email: dungtmht@gmail.com

Ngày nhận bài: 29/6/2021

Ngày phản biện khoa học; 25/7/2021

Ngày duyệt bài: 20/8/2021
General Hospital of Ha Tinh province from July 2017 to April 2019. Results: 47 patients with 30 men and 17 women, mean age $61.4 \pm 11.9$. Pathologies indicated to implant 2-chamber permanent pacemaker: level 2 and 3 atrioventricular block accounted for $42.6 \%$; Sinus node failure syndrome accounted for $57.5 \%$. The mean excitation threshold of the right atrial electrode should be $0.9 \pm 0.2 \mathrm{~V}$; of right ventricular electrode $0.5 \pm 0.2 \mathrm{~V}$. The mean left ventricular ejection fraction EF after 3 months of implantation was measured to be $57.3 \pm 8.5$. None of the patients had complications such as pericardial hemorrhage, pocket infection, and electrode failure. Conclusion: The 2-chamber MTNTVV culture technique is a safe, effective method, with a high success rate and low complications. When it is implemented successfully at the provincial level, it will help reduce the load on hospitals at higher levels.

Keywords: Two-chamber implantation of a permanent pacemaker, RLP

\section{I. ĐĂT VẤN ĐỀ}

RLNT chậm là một bệnh lý thường gặp trên lâm sàng, bệnh thường gây ra các biến chứng nặng nề như choáng, ngất, thậm chí đột tử cho người bệnh. Điêuu trị nội khoa bằng các thuốc tăng nhịp tim gân như không có hiệu quả và còn để lại nhiều tác dụng không mong muốn. MTNTVV là giải pháp hàng đâu hiện nay, mang tính hiệu quả và lâu dài để điều trị các RLNT chậm không hồi phục. Nhiêu nghiên cứu cho thấy đến nay MTNTVV không chỉ điêu trị triệu chứng, mà còn cải thiện chất lượng cuộc sống và cải thiện tỉ lệ sống còn cho bệnh nhân, đặc biệt là MTNTVV 2 buồng.

Tại Việt Nam kỹ thuật cấy MTNTVV đã được thực hiện ở nhiêu bệnh viện trên toàn quốc. Khoa Tim mạch-Bệnh viện đa khoa tỉnh Hà Tĩnh đã triển khai cấy MTNTVV 1 buồng từ năm 2013, từ năm 2016 đến nay cây máy 2 buông và đi vào hoạt động thường quy, trung bình mỗi năm từ 50 - 70 máy. Xuất phát từ thực tễ đó, chúng tôi tiến hành nghiên cứu đề tài này với mục tiêu: 
"Khảo sát đăc điểm lâm sàng, cân lâm sàng của bệnh nhân RLNT chậm có chi định cây MTNTVV 2 buồng và đánh giá hiệu quả kỹ thuật cây MTNTVV 2 buồng".

\section{II. ĐỐI TƯỢNG VÀ PHƯƠNG PHÁP NGHIÊN CỨU}

2.1. Thiết kế nghiên cứu: Nghiên cứu thuần tập tiến cứu

\section{2. Đối tượng nghiên cứu:}

Tiêu chuẩn lựa chọn. Đối tượng nghiên cứu là những bệnh nhân được chẩn đoán RLNT chậm có chỉ định cấy MTNTVV 2 buồng tại khoa Tim mạch - Bệnh viện đa khoa tỉnh Hà Tình từ tháng 7/2017 đển tháng 4/2019. Tiêu chuẩn chẩn đoán RLNT chậm và chỉ định cấy MTNTVV dựa theo khuyến cáo của Hội Tim Mạch Việt Nam và các Hội Tim Mạch Hoa Kỳ, Hội Tim Mạch Châu Âu. Các đối tượng được lựa chọn tuần tự theo thời gian không phân biệt lứa tuổi, giới tính.

Tiêu chuẩn loại trừ. Bệnh nhân không theo dõi, khám lại định kỳ sau khi cãy máy tạo nhịp tim vĩnh viễn. Bệnh nhân không đồng ý tham gia vào nghiên cứu.

2.3. Các bước tiến hành nghiên cứu: Hỏi bênh và khám lâm sàng đầy đủ khi vào viên, đăc biệt là các dấu hiệu do nhịp châm gây ra: Choáng, xiu, ngất, hoa mắt chóng mặt...

Làm đây đủ các xét nghiêm: Điên giải đồ, chức năng gan, thận, siêu âm tim, ĐTĐ và Holter ĐTĐ...

Giải thích cho gia đình và bệnh nhân về thủ thuât sắp thực hiên.

Kháng sinh dự phòng trước thủ thuật.

Tiến hành thủ thuật cấy máy tạo nhịp tim vĩnh viễn 2 buồng dưới da.

Bệnh nhân được điều trị nội khoa theo phác đồ trước, trong và sau phẫu thuật, kháng sinh dự phòng trong 7 ngày sau cấy máy.

Bệnh nhân được theo dõi các biến chứng: tụ máu, nhiễm trùng, tràn khí màng phổi, máy mất dẫn,...

Khám và theo dõi bệnh nhân sau 3 tháng khám định kỳ, làm các xét nghiệm siêu âm tim, ĐTĐ khi bênh nhân tái khám.

2.4. Xử lý số liệu: Sử dụng phần mềm SPSS 16.0. Các biến định lượng được thể hiện dưới dạng trung bình và độ lệch chuẩn. Các biến định tính thể hiện dưới dạng tỉ lệ phần trăm.

\section{KẾT QUẢ NGHIÊN CỨU}

Trong thời gian từ 7/2017 đến 4/2019, chúng tôi đã tiến hành nghiên cứu trên 47 bệnh nhân được chẩn đoán các rối loạn nhịp tim chậm và cấy máy tạo nhịp tim vĩnh viễn 2 buồng tại khoa Tim mạch -Bệnh viện đa khoa tỉnh Hà Tĩnh.

3.1. Đặc điểm chung. Độ tuổi trung bình trong nghiên cứu là $61,4 \pm 11,9$, trong đó bệnh nhân nhiều tuổi nhất là 94 tuổi, bệnh nhân ít tuổi nhất là 45 tuổi.

Trong nghiên cứu của chúng tôi có 30 bênh nhân nam, chiếm 63,8\%. Nữ giới có 17 bệnh nhân chiếm $36,2 \%$.

3.2. Đặc điểm lâm sàng và cận lâm sàng

Bảng 1. Phân bố chi định cây máy tạo nhịp tim vĩnh viễn 2 buồng

\begin{tabular}{|c|c|c|}
\hline Chỉ định cây máy & $\begin{array}{c}\text { Số lượng } \\
\text { bệnh nhânn }\end{array}$ & Tỉ lệ \% \\
\hline Block nhĩ - thất & 20 & $42,6 \%$ \\
\hline Hội chứng suyy nút xoang & 27 & $57,4 \%$ \\
\hline Tống & $\mathbf{4 7}$ & $\mathbf{1 0 0} \%$ \\
\hline
\end{tabular}

Bảng 2. Phân bố các lý do nhập viện

\begin{tabular}{|c|c|c|}
\hline $\begin{array}{c}\text { Triệu chứng lâm } \\
\text { sàng }\end{array}$ & $\begin{array}{c}\text { Số lượng } \\
\text { bệnh nhân }\end{array}$ & $\begin{array}{c}\text { Tỉ lệ } \\
\text { \% }\end{array}$ \\
\hline Chóng mặt & 21 & $44,7 \%$ \\
\hline Hồi hộp, tức ngực & 19 & $40,4 \%$ \\
\hline Ngất, xỉu & 7 & $14,9 \%$ \\
\hline Tống & $\mathbf{4 7}$ & $\mathbf{1 0 0 \%}$ \\
\hline
\end{tabular}

100

$74,5 \%$

0

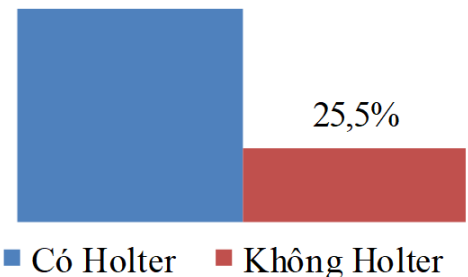

Biểu đồ 1. Tỉ lệ cây máy tạo nhịp dựa trên kết quả Holter DTE 24 giờ

3.3. Các thông số điện cực máy tạo nhịp tim vĩnh viến

Bảng 3. Các thông số cấy máy tạo nhịp tim vĩnh viến 2 buồng

\begin{tabular}{|c|c|c|c|}
\hline Các thông số & $\begin{array}{c}\text { Đơn vị } \\
\text { đo }\end{array}$ & $\begin{array}{c}\text { Điện cực } \\
\text { nhî̉ phải }\end{array}$ & $\begin{array}{c}\text { Điệ̂n cực } \\
\text { thất phải }\end{array}$ \\
\hline $\begin{array}{c}\text { Ngưỡng kích } \\
\text { thích trung bình }\end{array}$ & $\begin{array}{c}\mathrm{V} \\
(\mathrm{Vôn})\end{array}$ & $0,9 \pm 0,4$ & $0,5 \pm 0,2$ \\
\hline $\begin{array}{c}\text { Biên đô̂ sóng } \mathrm{P} / \\
\text { sóng R trung } \\
\text { bình }\end{array}$ & $\begin{array}{c}\mathrm{mV} \\
\text { (mili } \\
\text { vôn) }\end{array}$ & $2,1 \pm 1,1$ & $9,2 \pm 3,8$ \\
\hline $\begin{array}{c}\text { Trở kháng trung } \\
\text { bình }\end{array}$ & $\begin{array}{c}\Omega \\
(\mathrm{Ohm})\end{array}$ & $768 \pm 176$ & $657 \pm 135$ \\
\hline
\end{tabular}

3.4. Đặc điếm chức năng tim trước và sau cây máy

Bảng 4. Phân suất tống máu EF trung bình trước và sau cấy máy

\begin{tabular}{|c|c|c|c|}
\hline & $\begin{array}{c}\text { Trước cây } \\
\text { máy }\end{array}$ & $\begin{array}{c}\text { Sau cây máy } \\
\mathbf{3} \text { tháng }\end{array}$ & $\mathbf{P}$ \\
\hline $\begin{array}{c}\text { Phân suất } \\
\text { tống máu (EF) } \\
\text { trung bình }\end{array}$ & $62,7 \pm 9,8$ & $57,3 \pm 8,5$ & $\begin{array}{c}\mathrm{p}> \\
0,05\end{array}$ \\
\hline
\end{tabular}


3.5. Một số biến chứng sớm: Tất cả bệnh nhân được cấy máy tạo nhịp tim vĩnh viễn 2 buồng trong nghiên cứu của chúng tôi tại Bệnh viện đa khoa tỉnh Hà Tĩnh không có bệnh nhân nào bị biến chứng sớm như: máy mất dẫn, tụ máu bao máy, tràn khí màng phổi, tràn máu màng ngoài tim,...

\section{BÀN LUẬN}

4.1. Đặc điểm chung. Chúng tôi nghiên cứu trên 47 bểnh nhân, tuổi trung bình $61,4 \pm 11,9$ trong đó bệnh nhân nhiều tuổi nhất là 94 tuối, bệnh nhân ít tuổi nhất là 45 tuổi.Điều này chứng tỏ phần lớn bệnh nhân mắc các bệnh lý rối loạn nhịp tim chậm có tuổi đời khá cao. Độ tuổi này cũng tương tự với nhiều nghiên cứu khác ở trong nước cũng như ngoài nước. Tỉ lệ nam giới chiếm $63,8 \%$ trong khi đó tỉ lệ này ở nữ giới là $36,2 \%$. Sự khác biệt về tỉ lệ nam nữ mắc các bệnh RLNT nói chung đã được đề cập trong nhiều nghiên cứu, nhưng đến nay vẫn chưa sáng tỏ.

4.2. Triệu chứng lâm sang. Có 7 bệnh nhân trong nghiên cứu của chúng tôi vào viện vì xuất hiện ngất ít nhất 1 lần (chiếm 14,9\%). Qua đó chúng ta có thể thây nhiều bệnh nhân có tình trạng bệnh cảnh khá nặng nề, chờ đến lúc các triệu chứng diễn ra một cách trầm trọng, nguy hiểm đe dọa đến tính mạng mới nhập viện. Nghiên cứu của tác giả Huỳnh Trung Cang ở bệnh viện Kiên Giang thì tỉ lệ bệnh nhân ngất khá cao, chiếm $71 \%$. Các triệu chứng thường gặp khác như chóng mặt, choáng váng mă̆t mày và hồi hộp tức ngực, lần lượt chiếm tî lệ là $44,7 \%$ và $40,4 \%$.

4.3. Phấn bố bệnh lý cây MTNTVV 2 buồng. Trong nghiên cứu của chúng tôi thì bệnh nhân mắc các bệnh lý về Block nhĩ thất cấp 2 , cấp 3 chiếm tỉ lệ 42,6\%. Có 27 bệnh nhân được chẩn đoán hội chứng suy nút xoang, chiếm tỉ lệ $57,5 \%$. Đây là hai nhóm bệnh lý chính thường gặp trên lâm sàng trong chỉ định cấy máy tạo nhịp tim vĩnh viễn 2 buồng. Đặc biệt với sự phát triển của y học hiện đại, trong bệnh lý suy nút xoang, phương pháp cấy máy tạo nhịp 2 buồng dần thay thế tạo nhịp 1 buồng vì có nhiêu ưu điểm hơn cũng như có tiên lượng tốt hơn về chức năng tim sau này.

4.4. Tính hữu dụng của Holter điện tâm đồ 24 giờ. Có 35 bệnh nhân (chiếm 74,5\%) trong nghiên cứu của chúng tôi được chỉ định cấy máy tạo nhịp tim vĩnh viển 2 buồng dựa trên kết quả của Holter ĐTĐ 24 giờ. Những bệnh nhân này nhập viện với các tình trạng nhức đầu chóng mặt, một số khác có các triệu chứng hồi hộp tức ngực, cảm giác tim đập chậm nhưng hình ảnh điện tâm đồ bề mặt lại không phản ánh được đầy đủ tình trạng nhịp tim của bệnh nhân. Kết quả Holter ĐTÐ 24 giờ đóng vai trò rất quan trọng trong chẩn đoán các rối loạn nhịp tim chậm, là một phương pháp chẩn đoán hiệu quả và mang tính toàn diện qua đó cho các bác sĩ một cái nhìn tổng quát về tình trạng bệnh nhân.

4.5. Các thông số điện cực máy tạo nhịp tim vĩnh viễn 2 buồng. Ngưỡng kích thích của điện cực tiểu nhĩ phải trung bình trong nghiên cứu của chúng tôi là $0,9 \pm 0,2 \mathrm{~V}$. Kết quả này phù hợp với tiêu chuẩn tạo nhịp nhĩ được khuyến cáo là $0,4 \mathrm{~V}-1,4 \mathrm{~V}$. Biên độ sóng $\mathrm{P}$ trung bình đo được trong nghiên cứu là $2,1 \pm 1,1 \mathrm{mV}$. Trỏ kháng trung bình là $768 \pm 176 \Omega$.

Trong nghiên cứu của chúng tôi, 100\% bệnh nhân đạt tiêu chuẩn ngưỡng tạo nhịp thất theo khuyến cáo là $0,3 \mathrm{~V}-1,2 \mathrm{~V}$, trong đó ngưỡng kích thích điện cực thất phải trung bình của chúng tôi là $0,5 \pm 0,2 \mathrm{~V}$. Biên độ sóng $\mathrm{R}$ trung bình là 9,2 $\pm 3,8 \mathrm{mV}$. Trở kháng trung bình là $657 \pm 135 \Omega$. Điện cực thất phải được chúng tôi cố định ở 2 vị trí chính là vách liên thất và mỏm thất phải, và ở cả 2 vị trí này thì các thông số đo được đều thỏa mãn các tiêu chuẩn theo khuyến cáo đặt ra trước đây. Do vậy trong thực hành lâm sàng thì tùy từng tình trạng bệnh nhân cũng như tình trạng bệnh lý mà lựa chọn vị trí tạo nhịp thất phù hợp.

4.6. Đặc điểm về chức năng tim sau cây máy tạo nhịp tim vĩnh viễn 2 buồng. Chúng tôi theo dõi bệnh sau cấy máy tạo nhịp tim vĩnh viễn 2 buồng sau 3 tháng, bệnh nhân đến khám lại được làm các xét nghiệm điện tâm đồ, siêu âm tim. Phân suất tống máu thất trái EF sau cây máy 3 tháng trung bình đo được là $57,3 \pm 8,5$. Nhiêu nghiên cứu lâm sàng trên thế giới đã chỉ ra rằng việc cấy máy tạo nhịp tim vĩnh viễn 2 buồng mang lại lợi ích lâu dài hơn cho bệnh nhân, tránh được sự mất đồng bộ nhĩ thất, nhờ đó làm giảm được tỉ lệ suy tim hơn so với việc cấy máy tạo nhịp tim vĩnh viễn 1 buồng. Tuy nhiên vì điều kiện thời gian cũng như một số lí do khác nên chúng tôi chỉ theo dõi được các thông số này sau 3 tháng.

4.7. Biến chứng sau cây máy: Tất cả 47 bệnh nhân được cấy máy tạo nhịp tim vĩnh viễn 2 buồng trong nghiên cứu của chúng tôi tại Bênh viện đa khoa tỉnh Hà Tĩnh không có bệnh nhân nào bị biến chứng sớm như: máy mất dẫn, tụ máu bao máy, tràn khí màng phổi, tràn máu màng ngoài tim. Trong thời gian triển khai kỹ thuật này tại bệnh viện chúng tôi không có trường hợp bệnh nhân nào tử vong. 


\section{KẾT LUẬN}

Qua nghiên cứu 47 bệnh nhân tại bệnh viện đa khoa tỉnh Hà Tĩnh, chúng tôi nhận thấy kỹ thuật cấy MTNTVV 2 buồng bước đầu triển khai thành công, là một phương pháp điều trị an toàn, hiệu quả, ít nguy hiểm với tỉ lệ biến chứng thấp. Sự thành công này góp phần tiết kiệm thời gian và chi phí điều trị cho bệnh nhân, qua đó làm giảm tải cho các bệnh viện tuyến trên.

\section{TÀI LIÊU THAM KHẢO}

1. Prystonsky, E.N., Cardiac Arrhythmias. 1994

2. Parsonnet, V., et al., An intracardia bipolar electrode for interim treatment of complete heart block. Am J Cardiol, 1962. 10: p. 261-5.

3. Larsson, B., et al., Lessons from the first patient with an implanted pacemaker: 1958-2001. Pacing Clin Electrophysiol, 2003. 26(1 pt 1): p.114-24.
4. Nguyễn Mạnh Phan, et al., Khuyến cáo của Hội Tim Mạch học Việt Nam về chỉ định đặt máy tạo nhịp. K̇huyến cáo về các bệnh lý tim mạch và chuyển hóa, 2008: p.217-234.

5. Belott. PH. Implant Technique, Cardiac pacing for clinician Second Edition, Fred M. Kusumoto, 2008: p.116-255.

6. Nguyễn Sỹ Huyên, Trân Thống, Nguyễn Phú Du, Ta Tiến Phước, Máy tao nhip tim cơ bản thực hành, Tạp chí Tim mạch học Việt Nam số 16, 1998: p.60.

7. Pham Như Hùng, Trân Song Giang, Trân Văn Đồng, Tạ Tiến Phước, Thực trang câyy máy tạo nhịp tim vĩnh viễn 1 buồng và 2 buồng tim trong chỉ định nhip chậm tại Viện tim mạch Quốc gia Việt Nam. Kỷ yểu tóm tắt các báo cáo khoa học, Đại hội Tim mach toàn quốc lần thứ 13, 2012: p.19-20.

8. Trân Thhông, Tạo nhịp thất với máy 2 buồng: Lợi hay hại? Hội nghị Tim mạch miên nam, 2009.

\section{ĐIỆN Đồ TĨNH MẠCH PHỔI Ở BỆNH NHÂN RUNG NHĨ KỊCH PHÁT}

\section{Phan Đình Phong ${ }^{1}$, Bùi Văn Nhơnn, Trần Tuấn Việt ${ }^{1}$, Đỗ Mạnh Cầm ${ }^{1}$}

\section{TÓM TẮT}

Nghiên cứu được tiến hành với muc tiêu mô tả đăc điểm điện đồ tĩnh mạch phổi ở bệnh nhân rung nhî kịch phát tại Viện Tim mạch Việt Nam. Kết quá cho thấy, điện đồ tĩnh mạch phổi đều được ghi nhận ởbệnh nhân rung nhĩ kịch phát (chiếm 100\%). Khoảng thời gian dẫn truyền nhĩ - tĩnh mạch phổi (khoảng APV) tối đa và trung bình ở tĩnh mạch phổi trên trái là dài nhất $(67,00 \pm 9,72 \mathrm{~ms}$ và $56,65 \pm 8,52 \mathrm{~ms}$, tương ứng). Hình dạng điện đồ tĩnh mach phổi thường gặp là điện đồ nhiều thành phần $(31,6 \% \pm 8,7 \%)$; hình dạng điện đồ tĩnh mạch phổi khác bao gồm điện đồ 3 pha $(29,5 \% \pm 9,1 \%)$, điện đồ 2 pha $(19,4 \% \pm 8,4 \%)$ và điện đồ kép $(5,8 \% \pm 5,9 \%)$. Điện đồ kép gặp nhiêu nhất ở tĩnh mạch phổi trên trái $(11,9 \% \pm 6,8 \%)$.

Tư khoá: Rung nhĩ kịch phát, điện đồ tĩnh mạch phổi, điện đồ nhiều thành phần, điện đồ kép.

\section{SUMMARY \\ PULMONARY VEIN POTENTIALS IN \\ PATIENTS WITH PAROXYSMAL ATRIAL FIBRILLATION}

Objectives: To describe pulmonary vein (PV) potentials in patients with paroxysmal atrial fibrillation at the Vietnam Heart Institute. The results showed that typical PV potentials were recorded all patients

\footnotetext{
${ }^{1}$ Trường Đại học Y Hà Nội

${ }^{2}$ Bệnh viện Đại học Y Hà Nội

Chịu trách nhiệm chính: Bùi Văn Nhơn

Email: drbuinhon@hmu.edu.vn

Ngày nhận bài: 25/6/2021

Ngày phản biện khoa học: 25/7/2021

Ngày duyệt bài 15/8/2021
}

withparoxysmal atrial fibrillation(100\%). The maximal and mean A-PV intervals in left superior pulmonary vein were longest $(67.00 \pm 9.72 \mathrm{~ms}$ và $56.65 \pm 8.52$ $\mathrm{ms}$, respectively).Types of pulmonary vein potentials were a higher prevalence ofmultiphasic $(31.6 \% \pm$ $8.7 \%)$; the others were included triphasic potentials $(29,5 \% \pm 9,1 \%)$, biphasic potentials $(19,4 \% \pm 8,4 \%)$, and double potentials was $5.8 \% \pm 5.9 \%$. The double potentials was a highest in left superior pulmonary vein $(11.9 \% \pm 6.8 \%)$

\section{Keywords:}

Paroxysmal atrial fibrillation,pulmonary vein potentials, multiphasic potentials, double potentials.

\section{I. ĐĂT VẤN ĐỀ}

Rung nhĩ là rối loạn nhịp tim thường gặp, xảy ra ở 1-2\% dân số. Tỷ lệ mới mắc và hiện mắc rung nhĩ có xu hướng cao ở các nước phát triển [1]. Tỷ lệ rung nhĩ kịch phát ước tính chiếm 3\% ở người trên 20 tuổi; tỉ lệ tăng cao ở người lớn tuổi và những bệnh nhấn mắc các bệnh như tăng huyết áp, suy tim, bệnh động mạch vành, bệnh lý van tim, béo phì, đái tháo đường, bệnh thận mạn tính [1]. Trung bình tỷ lệ mắc mới của rung nhĩ khoảng $0,1 \%$ mỗi năm ở người dưới 40 tuổi, và tăng lên nhanh ở người trên 60 tuổi với 1,5-2,0\% [2]. Theo nghiên cứu Framingham, tỷ lệ hiên mắc rung nhĩ từ 0,5\% ở tuổi 50-59 tăng nhanh tới 8,8\% ở tuổi 80-89. Tỷ lệ mắc rung nhĩ kịch phát trong số rung nhĩ là cao: theo Godfredsen là 35,0\%, theo Takahashi là 40,2\%, theo Phillips là 62,0\%. Cùng với xu hướng gia tăng tỷ lệ mắc thì gánh nặng của rung nhĩ cũng 